\title{
François Rouget, Ronsard et le livre. Étude de critique génétique et d'histoire littéraire. Première partie: Lectures et textes manuscrits
}

\section{Dario Cecchetti}

\section{(2) OpenEdition \\ Journals}

\section{Edizione digitale}

URL: http://journals.openedition.org/studifrancesi/5901

DOI: 10.4000/studifrancesi.5901

ISSN: 2421-5856

\section{Editore}

Rosenberg \& Sellier

\section{Edizione cartacea}

Data di pubblicazione: 1 mai 2011

Paginazione: 157

ISSN: 0039-2944

\section{Notizia bibliografica digitale}

Dario Cecchetti, «François Rouget, Ronsard et le livre. Étude de critique génétique et d’histoire littéraire Première partie: Lectures et textes manuscrits», Studi Francesi [Online], 163 (LV | I) | 2011, online dal 30 novembre 2015, consultato il 12 janvier 2021. URL: http://journals.openedition.org/studifrancesi/5901 ; DOI: https://doi.org/10.4000/studifrancesi.5901

Questo documento è stato generato automaticamente il 12 janvier 2021.

\section{cc) (†) $\odot$}

Studi Francesi è distribuita con Licenza Creative Commons Attribuzione - Non commerciale - Non opere derivate 4.0 Internazionale. 


\title{
François Rouget, Ronsard et le livre. Étude de critique génétique et d'histoire littéraire. Première partie: Lectures et textes manuscrits
}

\author{
Dario Cecchetti
}

\section{NOTIZIA}

FRANÇOIS ROUGET, Ronsard et le livre. Étude de critique génétique et d'histoire littéraire. Première partie: Lectures et textes manuscrits, Genève, Droz, 2010 («Cahiers d'Humanisme et Renaissance, vol. 95»), pp. 288.

1 Viene offerta agli studiosi la prima parte di un lavoro di ampio respiro e di fondamentale importanza inteso a ricostruire «la traiettoria biografica, sociale e culturale di Ronsard, studiata secondo due prospettive teoriche e metodologiche strettamente associate, quella bibliologica o genetica e quella letteraria». Come l'A. stesso si premura di precisare, il termine "genetico» è usato in un'accezione più vasta di quella impiegata abitualmente degli specialisti moderni di critica genetica, che lo riservano allo studio della genesi dei manoscritti: tale concetto è applicato qui all'analisi dei diversi stati materiali e letterari di un testo, sia manoscritto che a stampa, il che permette di considerare le varianti delle poesie stampate a pieno titolo come elementi della loro genesi. La ricostruzione della suddetta traiettoria ronsardiana, «cercando di osservare l'opera nel suo farsi e di descrivere l'evoluzione del progetto letterario, creativo, nelle sue relazioni con le condizioni materiali del libro (manoscritto e a stampa), vorrebbe evidenziare come Ronsard ha tratto profitto dalla produzione e dal commercio del libro per affermare il proprio statuto di poète royal e per dare la sua impronta alla poesia del Cinquecento». François Rouget prevede due parti per la sua ricerca: nella prima, ora pubblicata, sono esaminati tutti gli aspetti della scrittura manoscritta in Ronsard (le annotazioni dei libri letti, la redazione di 
documenti relativi alla sua vita privata, la copia di testi letterari scritti sotto la sua dettatura o ricopiati da scrivani). Un secondo volume, di prossima pubblicazione, si occuperà delle opere a stampa del poeta.

Dopo un primo breve capitolo (L'imaginaire du livre chez Ronsard, pp.19-36), in cui si chiarisce quale posto e quale ruolo il libro occupi nell'universo mentale di Ronsard studiando appunto la rappresentazione del libro nella produzione del poeta-, in un secondo capitolo (La formation du goût: Ronsard et sa librairie, pp.37-103) vengono analizzate le annotazioni di lettura disseminate nei libri appartenuti a Ronsard, evocando i primi passi del poeta nella scoperta della letteratura e poi le considerazioni suscitate dai suoi maestri (Dorat, Turnèbe), sempre con l'intento di determinare, attraverso le annotazioni dei testi letti, l'uso intertestuale che ne viene fatto nella composizione delle opere. In un terzo capitolo (Avant-texte et texte: genèse manuscrite de l'œuvre ronsardienne, pp. 105-195), dopo l'analisi delle letture ronsardiane, l'A. insiste «sulla genesi poetica propriamente detta per sottolineare come Ronsard si sia servito delle diverse composizioni manoscritte delle sue poesie per farle circolare a Corte». Sviluppa inoltre «una riflessione sulla tappa preeditoriale della poetica ronsardiana, seguendo l'evoluzione genetica di alcune poesie e la costruzione della loro unità», tenuto conto che Ronsard «a partire dalla scrittura manoscritta non cessa di correggersi per produrre diverse versioni delle sue poesie, come ben dimostra la genesi dei libri della Franciade, o dei Discours, o degli Hymnes». Viene infine sottolineata la diffusione che conobbe la poesia ronsardiana sotto forma di manoscritti e viene offerta per la prima volta una sintesi sulla questione dei manoscritti di Ronsard. In attesa, quindi, del secondo volume consacrato allo studio delle peripezie editoriali del testo ronsardiano, non possiamo che felicitarci della pubblicazione di un così utile strumento di lavoro. 